\title{
PENGARUH APLIKASI ABAMEKTIN TERHADAP KELIMPAHAN LALAT PENGOROK DAUN DAN PARASITOIDNYA PADA PERTANAMAN KENTANG
}

\author{
Purnomo $^{1}$
}

\author{
ABSTRACT
}

Effect of application of abamectine on the abundance of leafminer flies and its parasitoids on potato fields. The objective of this research was to investigate the effect of the application of abamectin insecticide on the infestation of potato leafminer and its parasitoid. The field experiment was conducted on potato fields in Pangalengan - Bandung, West Java in 2000. The results showed that the abamectin-insecticide significantly reduced the plant damage intensities, the number of mining per plants, and the percentage of leaf damage. In addition, the application of abamectin insecticide was not significanlty affected the level of parasitism and the number of parasitioid Hemiptarsemus varicornis (Girault) (Hymenoptrea: Eulophidae) and Opius sp. (Hymenoptera: Braconidae) that were emerged from leaf sample. The abamectin insecticide has a good possibilities to be used as an altenative for controlling of the leafminers before another technology was found.

Key words: Liriomyza huidobrensis, abamectin, parasitoid, Hemiptarsenus varicornis, Opius sp.

\section{PENDAHULUAN}

Kerusakan tanaman kentang oleh lalat pengorok daun, Liriomyza huidobrensis (Blanchard) (Diptera: Agromyzidae) pada beberapa tahun terakhir ini cukup tinggi. Kerusakan tersebut berakibat pada rendahnya produksi kentang per satuan luas sehingga menimbulkan kerugian besar bagi petani kentang. Shepard et al. (1998) melaporkan bahwa petani kentang di Pangalengan-Bandung, Jawa Barat dapat kehilangan hasil panen hingga $30 \%$ akibat serangan L. huidobrensis, Hasil pengamatan di lapangan memperlihatkan bahwa di samping menyerang kentang, L. huidobrensis juga menyerang tanaman sayuran lainnya seperti tomat, mentimun, dan beberapa jenis kacang-kacangan.

Dari hasil survei Rauf et al. (2000) terungkap bahwa kebanyakan petani kentang di Jawa dan Sumatera menggunakan insektisida untuk mengendalikan $L$. huidobrensis. Lebih lanjut mereka melaporkan bahwa lebih dari 35 jenis insektisida konvensional telah digunakan petani untuk mengendalikan hama tersebut. Seringkali petani mengaplikasikan insektisida dengan frekuensi dua hingga tiga kali per minggu, bahkan kadangkala petani mencampur dua hingga tiga jenis insektisida sekaligus. Namun demikian hasil yang diperoleh petani sering kurang memuaskan.

Kegagalan penggunaan insektisida untuk mengatasi serangan $L$. huidobrensis dapat disebabkan oleh banyak faktor. Dua di antaranya adalah (a) ketidakmampuan insektisida mencapai sasaran, yakni larva yang berada di dalam korokan dan (b) adanya $L$. huidobrensis yang telah resisten terhadap beberapa jenis insektisida. Parrella (1987) berpendapat bahwa beberapa spesies Liriomyza cepat menjadi resisten akibat mendapat perlakuan insektisida berulang kali, di pihak lain musuh alami Liriomyza justru lebih rentan. Macdonald (1991) menyatakan bahwa $L$. huidobrensis toleran terhadap insektisida golongan organofosfat namun resisten terhadap golongan piretroid.

Pada saat sekarang telah beredar di pasaran beberapa jenis insektisida yang menurut petani cukup mampu menekan serangan lalat pengorok daun kentang, hanya saja harganya cukup mahal. Insektisida tersebut bersifat translamina, salah satunya berbahan aktif abamektin. Menurut Jansson \& Dybas (1997) abamektin adalah salah satu homolog avermektin yang diperoleh dari hasil fermentasi Streptomyces avermitilis. Selain terhadap serangga, senyawa tersebut dikenal efektif dalam mengatasi nematoda dan tungau. Penelitian ini bertujuan untuk mengkaji pengaruh aplikasi insektisida abamektin terhadap kerusakan tanaman kentang $L$. huidobrensis dan pengaruhnya terhadap parasitoid.

Penelitian tentang pengaruh penggunaan insektisida berbahan aktif abamektin ini dilaksanakan di Desa Sukamanah Kecamatan Pangalengan, Bandung dan berlangsung dari bulan Agustus hingga

\footnotetext{
${ }^{1}$ Dosen Jurusan Proteksi Tanaman Fakultas Pertanian Universitas Lampung,

Jl. Prof. Soemantri Brodjonegoro, No. 1 Bandar Lampung
} 
Desember 2000. Perlakuan disusun dalam rancangan acak kelompok (RAK), terdiri atas lima perlakuan frekuensi aplikasi dan empat ulangan. Frekuensi aplikasi insektisida berbahan aktif abamektin meliputi: (1) tanpa aplikasi (kontrol), (2) dua kali aplikasi pada tanaman berumur 7 dan 9 minggu setelah tanam (mst), (3) tiga kali aplikasi pada tanaman berumur 5, 7, dan 9 mst, (4) empat kali aplikasi pada tanaman berumur 7, 8, 9, dan $10 \mathrm{mst}$, dan (5 ) enam kali aplikasi pada tanaman kentang berumur $5,6,7,8,9$, dan 10 mst.

Untuk percobaan ini diperlukan 20 petak percobaan, masing-masing berukuran $4 \mathrm{~m} \times 5 \mathrm{~m}$. Pada setiap petak percobaan ditanam benih kentang dengan jarak tanam $75 \mathrm{~cm} \times 30 \mathrm{~cm}$. Dengan demikian terdapat 75 tanaman atau rumpun kentang untuk setiap petak percobaan.

Penanaman benih kentang dilakukan pada lahan yang telah diolah dan diberi pupuk kandang dengan dosis satu $\mathrm{kg}$ per lubang tanam. Pada umur 4 mst diberi pupuk buatan dengan dosis $4 \mathrm{~g}$ urea, $15 \mathrm{~g}$ $\mathrm{ZA}, 10 \mathrm{~g} \mathrm{SP}$, dan $10 \mathrm{~g} \mathrm{KCl}$ per lubang tanam. Pada umur 4 mst tersebut juga dilakukan pembubunan tanaman yang pertama sehingga tanaman kentang terlihat seperti tumbuh di guludan. Pembubunan kedua dilakukan pada tanaman berumur $7 \mathrm{mst}$, yakni bersamaan dengan pengikatan tanaman dengan ajir. Selama masa pertumbuhannya, tanaman kentang juga disemprot dengan fungisida bila telah terlihat adanya bercak serangan Phytophthora pada daunnya.

Perlakuan penyemprotan insektisida abamektin menggunakan insektisida bermerek dagang Agrimec 18 EC. Konsentrasi yang digunakan adalah $0,5 \mathrm{ml} / 1$ dengan dosis $500 \mathrm{l} / \mathrm{ha}$, atau 1 liter untuk 20 $\mathrm{m}^{2}$.

Pengamatan kerusakan tanaman dilakukan pada saat tanaman berumur 5, 7, dan 9 mst. Pengamatan dilakukan dengan cara mengamati dan menghitung seluruh daun yang terdapat pada satu tanaman. Setiap daun diamati, apakah terdapat korokan larva atau tidak. Daun yang terkorok dianggap sebagai daun rusak dan ditentukan persentase kerusakannya dengan plastik transparan yang telah diberi garis seperti kertas milimeter blok. Dengan cara pengamatan ini selain dapat ditentukan persentase daun rusak, dapat juga ditentukan banyaknya korokan per tanaman. Pengamatan kerusakan tanaman dilakukan terhadap lima tanaman untuk setiap petak percobaan. Intensitas kerusakan dihitung dengan rumus intensitas kerusakan seperti berikut: persentase kerusakan daun pada satu tanaman

$\Sigma$ daun pada satu tanaman X $100 \%$

Pengamatan terhadap kemunculan parasitoid dilakukan pada tanaman kentang yang berumur 5 mst hingga $10 \mathrm{mst}$. Pengamatan dilakukan dengan mengumpulkan daun tanaman kentang yang terkorok oleh larva L. huidobrensis pada masing-masing cawan (diameter $6 \mathrm{~cm}$ dan tinggi $5 \mathrm{~cm}$ ) yang tertutup rapat. Untuk setiap petak percobaan diambil 20 daun tanaman yang terkorok larva instar 2 atau 3. Sebelumnya, selembar kertas tissu telah diletakkan pada bagian alas cawan dengan maksud untuk menyerap air yang menguap dari daun. Dengan cara ini diharapkan daun tidak cepat membusuk. Banyaknya imago lalat yang muncul, jumlah pupa yang gagal, dan jenis serta banyaknya imago parasitoid yang muncul diamati dicatat.

Data yang diperoleh dianalisis dengan sidik ragam dan dilanjutkan dengan pengujian nilai tengah menggunakan Uji Duncan pada taraf nyata $5 \%$.

\section{HASIL DAN PEMBAHASAN}

Kerusakan tanaman kentang karena korokan larva $L$. huidobrensis pada mulanya rendah kemudian meningkat bersamaan semakin tuanya umur tanaman. Hal itu ditunjukkan oleh persentase kerusakan daun dan banyaknya korokan per tanaman (Tabel 1). Pada tabel tersebut juga terlihat bahwa aplikasi insektisida abamektin mampu menekan kerusakan tanaman.

Intensitas kerusakan tanaman pada awal masa pertumbuhan tanaman kentang umumnya selalu rendah karena rendahnya populasi larva. Cisneros dan Mujica (1999) berpendapat bahwa kegagalan menetasnya telur Liriomyza biasa dijumpai pada daun-daun tanaman kentang yang masih muda. Ekstrusi telur merupakan penyebab utama terjadinya kegagalan penetasan telur.

Aplikasi insektisida abamektin dimulai ketika tanaman kentang berumur 5 mst. Oleh karena itu, kerusakan tanaman pada $5 \mathrm{mst}$ belum terpengaruh oleh perlakuan insektisida abamektin. Pada saat tanaman kentang berumur 7 mst, kerusakan tanaman tertinggi terjadi pada tanaman yang tidak mendapat 
Tabel 1. Pengaruh aplikasi abamektin terhadap jumlah korokan dan persentase daun rusak

\begin{tabular}{|c|c|c|c|c|c|c|}
\hline \multirow{2}{*}{$\begin{array}{l}\text { Aplikasi } \\
\text { Abamektin }\end{array}$} & \multicolumn{3}{|c|}{$\begin{array}{l}\text { Jumlah korokan per tanaman } \\
\text { pada umur tanaman (mst) }\end{array}$} & \multicolumn{3}{|c|}{$\begin{array}{l}\text { Persentase daun rusak per tanaman } \\
\text { pada umur tanaman (mst) }\end{array}$} \\
\hline & 5 & 7 & 9 & 5 & 7 & 9 \\
\hline $\begin{array}{l}0 \text { kali } \\
\text { (kontrol) }\end{array}$ & $2,10 \mathrm{a}$ & $50,85 \mathrm{~b}$ & $87,55 \mathrm{bc}$ & $1,13 a b$ & $13,80 \mathrm{~b}$ & $20,98 \mathrm{~b}$ \\
\hline $\begin{array}{l}2 \mathrm{kali} \\
(7 ; 9 \mathrm{mst})\end{array}$ & $3,16 \mathrm{a}$ & $41,00 \mathrm{ab}$ & $73,75 \mathrm{abc}$ & $1,47 \mathrm{ab}$ & $11,53 \mathrm{ab}$ & $18,79 \mathrm{~b}$ \\
\hline $\begin{array}{l}3 \mathrm{kali} \\
(5 ; 7 ; 9 \mathrm{mst})\end{array}$ & $0,60 \mathrm{a}$ & $35,70 \mathrm{ab}$ & $55,35 \mathrm{ab}$ & $0,44 \mathrm{a}$ & $10,84 \mathrm{ab}$ & 14,82 a \\
\hline $\begin{array}{l}4 \mathrm{kali} \\
(7-10 \mathrm{mst})\end{array}$ & $1,50 \mathrm{a}$ & 22,30 a & 38,55 a & $1,26 \mathrm{ab}$ & $7,76 \mathrm{a}$ & 11,38 a \\
\hline $\begin{array}{l}6 \mathrm{kali} \\
(5-10 \mathrm{mst})\end{array}$ & $4,70 \mathrm{a}$ & $31,85 \mathrm{a}$ & 39,40 a & $3,02 \mathrm{~b}$ & $10,62 \mathrm{ab}$ & $11,73 \mathrm{a}$ \\
\hline Nilai $F$ & 1,90 & 2,75 & 17,50 & 1,42 & 1,44 & 12,96 \\
\hline Nilai P & 0,16 & 0,07 & 0,00 & 0,28 & 0,27 & 0,00 \\
\hline
\end{tabular}

Keterangan: - angka yang diikuti oleh huruf yang sama pada arah vertikal tidak berbeda nyata menurut uji Duncan pada taraf $5 \%$.

Tabel 2. Pengaruh aplikasi abamektin terhadap tingkat parasitisasi

\begin{tabular}{l|cccccc}
\hline \multirow{2}{*}{$\begin{array}{l}\text { Aplikasi } \\
\text { Abamektin }\end{array}$} & \multicolumn{6}{|c}{ Tingkat parasitisasi (\%) } \\
\cline { 2 - 7 } pada umur tanaman (mst) \\
\hline 0 kali (kontrol) & 0,00 & 27,96 & 34,50 & 36,81 & 40,30 & 27,47 \\
$\begin{array}{l}2 \text { kali } \\
(7 ; 9 \text { mst) }\end{array}$ & 8,56 & 28,64 & 30,09 & 29,53 & 43,90 & 26,39 \\
$\begin{array}{l}3 \text { kali } \\
(5 ; 7 ; 9 \text { mst) }\end{array}$ & 5,88 & 26,49 & 21,62 & 25,31 & 43,03 & 27,91 \\
$\begin{array}{l}4 \text { kali } \\
(7-10 \text { mst) }\end{array}$ & 3,75 & 27,78 & 38,48 & 26,95 & 44,23 & 27,66 \\
$\begin{array}{l}6 \text { kali } \\
\text { (5-10 mst) }\end{array}$ & 4,17 & 26,57 & 31,31 & 35,92 & 41,75 & 29,43 \\
\hline Nilai F & 0,58 & 0,08 & 0,70 & 0,96 & 0,11 & 0,09 \\
\hline Nilai P & 0,68 & 0,99 & 0,60 & 0,46 & 0,98 & 0,99 \\
\hline
\end{tabular}

Keterangan: - tidak ada perbedaan antar-perlakuan (arah vertikal) pada semua pengamatan pada taraf nyata $5 \%$ 
Tabel 3. Pengaruh aplikasi abamektin terhadap munculnya imago $H$. varicornis dan Opius sp.

\begin{tabular}{|c|c|c|c|c|c|c|c|c|c|c|c|c|}
\hline \multirow{2}{*}{$\begin{array}{l}\text { Aplikasi } \\
\text { Abamektin }\end{array}$} & \multicolumn{6}{|c|}{$\begin{array}{l}\text { H.. varicornis (ekor) } \\
\text { pada umur tanaman (mst) }\end{array}$} & \multicolumn{6}{|c|}{$\begin{array}{c}\text { Opius sp.(ekor) } \\
\text { pada umur tanaman (mst) }\end{array}$} \\
\hline & 5 & 6 & 7 & 8 & 9 & 10 & 5 & 6 & 7 & 8 & 9 & 10 \\
\hline $\begin{array}{l}0 \text { kali } \\
\text { (kontrol) }\end{array}$ & 0,00 & 8,00 & 6,00 & 6,00 & 3,50 & 0,00 & 0.00 & 0,50 & 4,00 & 6,25 & 8,50 & 7,75 \\
\hline $\begin{array}{l}2 \text { kali } \\
(7 ; 9 \mathrm{mst})\end{array}$ & 2,00 & 9,50 & 7,75 & 2,50 & 3,00 & 1,25 & 0,00 & 0,75 & 3,25 & 6,25 & 9,50 & 6,75 \\
\hline $\begin{array}{l}3 \text { kali } \\
(5 ; 7 ; 9 \mathrm{mst})\end{array}$ & 1,00 & 12,75 & 7,25 & 3,75 & 0,00 & 1,25 & 0,00 & 0,00 & 0,00 & 5,00 & 13,75 & 7,50 \\
\hline $\begin{array}{l}4 \text { kali } \\
(7-10 \mathrm{mst})\end{array}$ & 0,75 & 7,75 & 10,25 & 3,50 & 3,75 & 0,50 & 0,00 & 0,00 & 1,75 & 5,25 & 9,25 & 5,25 \\
\hline $\begin{array}{l}6 \text { kali } \\
(5-10 \mathrm{mst})\end{array}$ & 1,50 & 7,0 & 9,50 & 2,75 & 2,50 & 0,75 & 0,00 & 0,00 & 0,00 & 8,50 & 9,75 & 5,50 \\
\hline Nilai F & 0,83 & 0,95 & 0,39 & 0,61 & 1,77 & 0,36 & & 0,77 & 0,79 & 0,37 & 0,61 & 0,99 \\
\hline Nilai P & 0,53 & 0,46 & 0,81 & 0,66 & 0,19 & 0,84 & & 0,56 & 0,55 & 0,83 & 0,66 & 0,44 \\
\hline
\end{tabular}

Keterangan: - tidak ada perbedaan antar-perlakuan (arah vertikal) pada semua pengamatan pada taraf nyata $5 \%$

perlakuan insektisida. Pada 9 mst, kerusakan tanaman dengan aplikasi 6,4 , dan 3 kali tidak berbeda nyata, tetapi berbeda dengan aplikasi 2 kali dan kontrol. Kenyataan-kenyataan ini menunjukkan betapa pun kecilnya, insektisida abamektin berperan bagi pencegahan peningkatan intensitas kerusakan tanaman ke araha yang lebih tinggi. Insektisida abamektin merupakan racun perut (Mrozik, 1997). Melalui aplikasi pada daun, insektisida tersebut akan mematikan serangga yang memakannya. Kontak fisik antara serangga dengan abamektin dilaporkan kurang efektif dalam mematikan serangga. Cox et al. (1995) menyatakan bahwa abamektin lebih efektif membunuh larva daripada imago L. trifolii.

Hasil penelitian Trumble (1985) menunjukkan bahwa aplikasi avermektin dapat menurunkan kelimpahan $L$ trifolii pada pertanaman seledri di Amerika Serikat. Begitu pula penelitian Weintraub \& Horowitz (1998) mendapatkan bahwa serangan dan kelimpahan $L$ huidobrensis lebih rendah pada pertanaman seledri yang diaplikasi dengan abamektin. Penelitian dengan hasil yang sama dilaporkan pada pertanaman kentang di Israel (Weintraub, 2001). Selain mematikan larva dalam daun, pengujian di laboratorium menunjukkan bahwa abamektin memperlihatkan sifat repelensi pada lalat $I_{\text {.. }}$ Irifolii (Parrella et al., 1988).

Perbedaan frekuensi aplikasi abamektin ternyata tidak berpengaruh terhadap tingkat parasitisasi parasitoid $L$. huidobrensis (Tabel 2). Pada tabel tersebut dapat dilihat bahwa tingkat parasitisasi tertinggi ditemukan pada tanaman kentang yang berumur 9 mst.

Imago parasitoid yang muncul dari daun terkorok larva $L$. huidobrensis adalah parasitoid larva Hemiptarsenus varicornis (Girault (Hymenoptera: Eulophidae) dan parasitoid larva-pupa Opius sp. (Hymenoptera: Braconidae). Pada Tabel 3 di bawah ini dapat dilihat kemunculan imago parasitoid $H$. varicornis dan Opius sp. dari daun contoh pada berbagai perlakuan aplikasi abamektin.

Beberapa peneliti di luar negeri ada juga yang melaporkan bahwa insektisida abamektin atau homolognya tidak berpengaruh buruk terhadap aktivitas parasitoid lalat pengorok. Trumble (1985) mendapatkan bahwa di antara avermektin, siromazin, dan metomil, hanya jenis yang disebut pertama yang tidak berpengaruh buruk terhadap parasitoid lalat pengorok daun. Sementara Weintraub (2001) melaporkan bahwa populasi parasitoid pada petakan 
kentang segera pulih setelah mendapat aplikasi abamektin. Namun, Weintraub dan Horowitz (1998) melaporkan bahwa insektisida translamina, termasuk abamektin, menurunkan kelimpahan parasitoid lalat pengorok daun pada tanaman seledri. Adanya perbedaan hasil-hasil penelitian tadi mungkin berhubungan dengan perbedaan kerentanan antar spesies parasitoid.

\section{SIMPULAN}

Aplikasi insektisida berbahan aktif abamektin pada saat dan frekuensi yang tepat terbukti mampu menekan serangan lalat pengorok daun $L_{\mathrm{s}}$ huidobrensis. Aktivitas dua spesies parasitoid $H$. varicornis dan Opius sp. terhadap L. huidobrensis tidak terpengaruh oleh aplikasi insektisida abamektin, oleh karenanya insektisida abamektin berpeluang dimanfaatkan dalam PHT lalat pengorok daun.

\section{SANWACANA}

Penulis mengucapkan terima kasih kepada Prof. Dr. Aunu Rauf (IPB) yang telah turut mendanai kegiatan penelitian ini. Data pada tulisan ini, yang disajikan dalam bentuk lain, merupakan sebagian dari disertasi penulis dengan ketua komisi pembimbing Prof. Dr. Aunu Rauf.

\section{DAFTAR PUSTAKA}

Cox D.L., D. Remick, J.A Lasota, \& R.A. Dybas. 1995. Toxicity of avermectin to Liriomyza trifolii (Diptera: Agromyzidae) larvae and adults. J. Econ. Entomol. 88(5): 1415 - 1419.

Cisneros, F. \& N. Mujica. 1999. The leafminer fly in potato: plant reaction and natural enemies as natural mortality factors. Di dalam: CIP, ed. Impact on Changing World, Program report 1997 - 1998. Lima Peru: International Potato Centre. hlm: $129-140$

Jansson, R.K. \& R.A Dybas. 1997. Avermectin: Biochemical mode of action, biological activity and agricultural importance. Di dalam: Isaac Ishaaya, Danny Degheele, eds. Insecticides with novel modes of action. Springer.

Macdonald, O.C. 1991. Responses of the alien leaf miners Liriomyza trifolii and Liriomyza huidobrensis (Diptera: Agromyzidae) to some pesticides scheduled for their control in the UK. Crop Protect. 10: 509-513.

Mrozik, H. 1997. Advances in research and development of avermectins. Di dalam: Briggs $\mathrm{GG}$, ed. Advances in the chemistry of Insect Control III. Saffron Walden Essex UK: Agr. Evo. UK Ltd. hlm: $54-71$

Parrella, M.P. 1987. Biology of Liriomyza. Annu. Rev. Entomol. 32: 201 - 224

Parrella, M.P., K.L. Robb, \& J.K. Virzi. 1988. Analysis of the impact of abamektin on Liriomyza trifolii (Burgess) (Diptera: Agromyzidae). Can. Ent. 120:831-837.

Rauf, A., B.M. Shepard, \& M.W. Johnson. 2000. Leafminer in vegetables, ornamental plants and weeds in Indonesia: surveys of host crops, species composition and parasitoids. Int. J. Pest Manage. 46 (4): 257 - 266.

Shepard, B.M., A. Braun, \& A.Rauf. 1998. Seasonal incidence of Liriomyza huidobrensis (Diptera: Agromyzidae) and its parasitoids on vegetables in Indonesia. Int. J. Pest Manage. 44: 43 47.

Trumble, J.T. 1985. Integrated pest management of Liriomyza trifolii: Influence of avermectin, cyromazine, and methomyl on leafminer ecology in celery. Agric. Ecosys. Environ. 12: 181-188.

Weintraub, P.G. 2001. Effects of cyromazine and abamectin on the pea leafminer Liriomyza huidobrensis (Diptera: Agromyzidae) and its parasitoid Diglyphus isaea (Hymenoptera: Eulophidae) in potatoes. Crop Protect. 20: 207213.

Weintraub, P.G. \& A.R. Horowitz. 1998. Effects of translaminar versus conventional insecticides on Liriomyza huidobrensis (Diptera: Agromyzidae) and Diglyphus isaea (Hymenoptera: Eulophidae) population in celery. J. Econ. Entomol. 91 (5): 1180 -1185. 